\title{
Strategic positioning of a motorcycle manufacturer within the Fourth Industrial Revolution
}

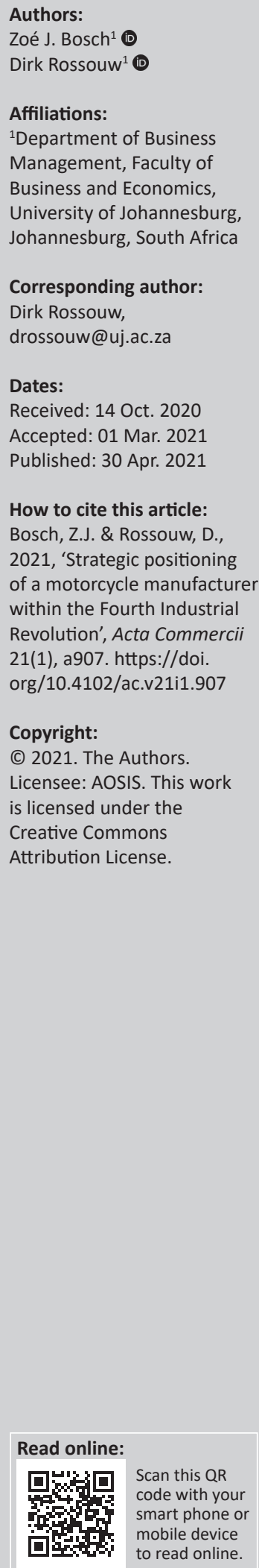

Orientation: Whilst the South African motorcycle industry faces a declining market, an additional challenge remains - the movement of the market into the Fourth Industrial Revolution (4IR), calling for strategic amendments.

Research purpose: The purpose of this research was to investigate and analyse the current strategies of a specific manufacturer, with the aim of establishing a strategic positioning suitable for the 4IR to gain a competitive advantage.

Motivation for the study: Acquired knowledge resulted in the establishment of various suggestions and recommendations, benefitting the manufacturer to gain a competitive advantage in the 4IR and thus strengthening its strategic positioning.

Research design, approach and method: Following an interpretive paradigm, a qualitative approach was used, allowing for in-depth analysis of 29 semi-structured interviews at five different dealerships and the regional head office in South Africa. Interviewees were selected using purposive and convenience sampling for the initial contact with the individual dealerships and regional head office of the motorcycle manufacturer. Thereafter, further interviewees were acquired based on the study requirements. Content analysis was applied to analyse the data.

Main findings: Some interviewees were less acquainted with the strategy and positioning of the manufacturer. Strong customer engagement strategies are necessary whilst targeting new markets.

Practical/managerial implications: Additional training is required, ensuring the equal acquisition of knowledge amongst employees. The introduction of technologies and the 4IR to customers is required to grow the market. New markets need to be identified and analysed to ensure efficient targeting.

Contribution/value-add: Whilst South Africa addresses the 4IR differently to Europe; this study's focus provides insights for the specific manufacturer to accurately conquer the changing environment.

Keywords: strategy; strategic positioning; competitive advantage; motorcycle manufacturer; Fourth Industrial Revolution.

\section{Introduction}

The changing environment and increased movement into the Fourth Industrial Revolution (4IR) resulted in a more intricate motorcycle industry in South Africa. Technological advancements and changes have led to increased customer demands, calling for quality and performance improvements and further innovations (Mtanga \& McCamel 2019). In addition, challenges brought forth by the declining market (Mtanga 2016) force motorcycle manufacturers to reconsider, adjust and modify their strategies and strategic positioning. It is, thus, deemed necessary to secure a competitive advantage within the changing environment of the 4IR (Alexander 2015). Therefore, the discussion to follow provides an overview on literature in support of the research question, starting with the dynamism of the market, followed by strategies and positioning, the 4IR within South Africa, the motorcycle industry and, lastly, the manufacturer itself.

\section{Dynamism and strategic positioning}

The 4IR has led to the emergence of innovative and creative strategies. Changing the course of direction, organisations are becoming more aggressive to sustain the dynamic competitive landscape that is increasingly revolving around technological advancements. These advancements 
have additionally led to modified products at an increased pace, following the implementation of innovations. Keeping up with these trends is vital for organisational success and survival (Garrett \& Welcher 2018).

To ensure survival and a competitive advantage in dynamic landscapes, it is necessary to consider multiple success factors, such as quality, service, innovation, speed, cost competitiveness and sustainability, which need to be reflected in the strategies implemented (Bateman, Snell \& Konopaske 2019). Drastic changes in the manufacturing industry have been realised, thus making it critical to accurately manage information (Low 2019). Inevitably, the motorcycle industry encounters challenges around legislation promoting environmental friendliness, resulting in the rise of electric-powered vehicles (Mitterreiter 2018). As these changes progress, further developments to the manufacturing processes and services are required as well as added modifications to the strategies.

Strategy entails a reflection of organisations' value chains, consisting of multiple procedures implemented in a unique way amongst industry rivals (Porter 2001). Strategy and planning thereof are, therefore, vital, as it provides guidance in recognising and accomplishing anticipated objectives whilst additionally providing for the evaluation of developments in comparison to competitors (Gartenstein 2018). Managers are required to make continuous assessments to ensure that the strategies meet the changing demands to remain competitive (Gamble, Peteraf \& Thompson 2017:7). An envisioned strategic positioning can, thus, be achieved through the implementation of diverse strategies and a thorough market analysis, ensuring a sustainable competitive advantage (Porter 1980; Prabhakar Rajkumar \& Abraham 2018:162).

Technological advancements are occurring at a rapid rate, forcing significant strategic changes to be made across industries. However, accepting and keeping up with the changing environments form part of the drivers of success, with the potential of exploiting new opportunities (Cloosterman 2018). Affecting both short-term production and long-term sustainability requires organisations to warrant reliability as well as assurance in technological improvements, and in the modification of strategies. Avoiding an unexpected crisis requires different strategies, adopting a remodelling nature whilst tolerating the changes in conditions and customer demands (Hickman \& Silva 2018).

\section{South Africa's readiness for the Fourth Industrial Revolution}

Africa is known to provide the least job possibilities in manufacturing industries, with little opportunities to remedy this. Globally, the African continent has been recognised to carry only $2 \%$ of the global manufacturing share. Thus, the 4IR in South Africa presents further challenges, as more jobs would be lost because of lack of skill and education to operate in an advanced environment. This may lead to the eventual replacement of workers by machines, or even outsourcing primary manufacturing activities to foreign countries with advanced economies, equipment and skills. Additionally, local markets are declining, as the spending power of South Africans is decreasing (Naudé 2017; Sutherland 2019).

Apart from the challenges instilled by the $4 \mathrm{IR}$, the South African motorcycle industry also faces several restrictions on trade, resulting in the manufacturing processes being relocated elsewhere. This leads to job losses and increased import costs, causing a decline in sales and trade. To counter this, the demand for aftermarket parts has, however, increased (Mtanga 2016). Although various opportunities are found in the manufacturing sector, it often remains unexploited. In addition to the aftermarket parts, the potential for growth in the low-cost motorcycle segment, targeting the lower income market by providing a cheaper and more time-efficient mode of transport, was identified (Mtanga \& McCamel 2019).

Since June 2014, a decline has been observed in new motorcycle registrations (eNatis 2019), although 50\% growth was forecasted in the smaller motorcycle segments (Cokayne 2016). The changes brought forth by the $4 I R$, and the fluctuating market conditions in South Africa, present an array of challenges to the motorcycle industry. In addition, the coronavirus disease 2019 pandemic in 2020 forced the South African motorcycle industry to close for a period of time, also leaving the industry unsettled. Thus, further analysis is necessary, defining the changes to be made to strategies and strategic positioning.

Despite these challenges, the motorcycle manufacturer under study managed to expand its motorcycle range. These expansions include several innovations and technological advancements to keep up with the changing environment and the 4IR (Mitterreiter 2018). The manufacturer has continuously focused on providing 'premium quality performance vehicles' to the market, ensuring customer demands are successfully met. This focus is adhered to with every decision and strategy, ensuring the core values are regularly portrayed (Anonymised Authors 2019a).

Aiming to guide the modification of strategies and strategic positioning suitable to the environmental changes, this research serves to draw conclusions in response to the primary objective, namely, to determine the motorcycle manufacturer's strategic positioning options for the 4IR in South Africa, ensuring a competitive advantage within the South African motorcycle industry. Subsequent to the primary objective, the following are the secondary objectives:

1. To establish an understanding of strategic positioning and the 4IR.

2. To establish the current strategic positioning and capabilities of the manufacturer.

3. To explore the current strategies impacting the positioning of the manufacturer.

4. To suggest strategies for positioning the motorcycle manufacturer in South Africa for the 4IR. 


\section{Research methods and design}

This study revolves around a specific motorcycle manufacturer in South Africa who has been achieving increased market share and profits in a declining market (AFP.com 2019). Providing a vast range of motorcycles, the core values are reflected in all strategies, resulting in the sale of a premium product and service. These impressions provide evidence that the manufacturer is currently known as one of the stronger rivals in the industry (Anonymised Authors 2019b). As the most popular range of motorcycles in South Africa consists of the adventure market, the manufacturer manifests most of its success in this area (Van der Walt 2017).

\section{Research instrument}

As depicted in Figure 1, the research follows an interpretive paradigm - allowing for inductive reasoning, a qualitative approach with a case study strategy was used (Denzin \& Lincoln 2008; Saunders, Lewis \& Thornhill 2019:196), thus acquiring insights and experiences (Thanh \& Thanh 2015). Using non-probability sampling methods, a combination of purposive sampling with an element of convenience sampling was applied. Convenience sampling was used during the selection of the different dealerships based on the convenience and accessibility to the researcher (Bryman \& Bell 2014). Purposive sampling was used during the selection of the type of job positions of the employees, which in turn was based on previously acquired knowledge and experiences of the industry (Etikan, Musa \& Alkassim 2016).

The population investigated was within Gauteng, South Africa, with the sample consisting of interviewees, employed

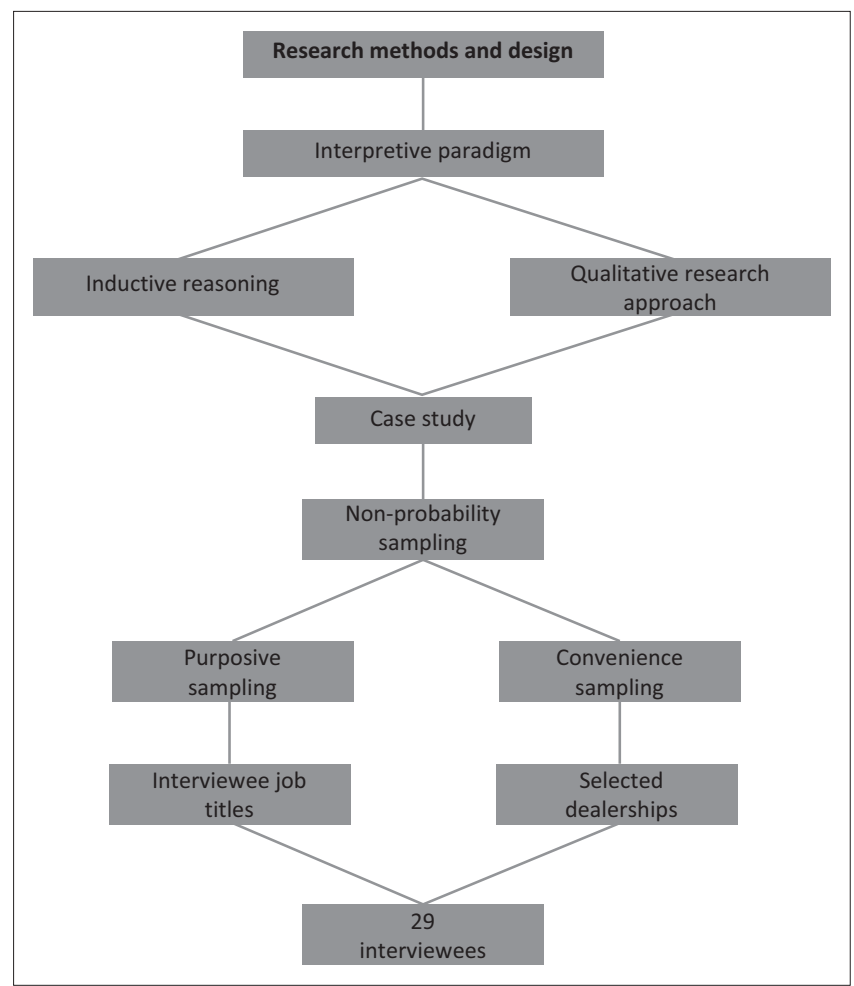

FIGURE 1: Research design outline. by the brand, from the regional head office, and five dealerships situated across the Gauteng province. Here a multistage sampling method is considered as Gauteng provides for the greatest number of dealerships across South Africa, thus providing an adequate sample of the population (Bryman \& Bell 2014). Dealerships located in the main regions of Gauteng were selected, providing an array of information. At the regional head office level, the managing director was interviewed, with a further five interviewees who provided beneficial information and insights about the manufacturer. Thereafter, the dealerships were approached, whereby the dealer principal was firstly interviewed, followed by further suggested interviewees, based on the specifications provided by the sampling methods. These specifications consisted of sales executives, an employee from the workshop and the accountant.

A total of 29 interviews were conducted with the intention of achieving saturation. The concept defines the time point of a research study when no additional or new information is found. Reaching this point of saturation allows for the collected data to be deemed as credible and comprehensive or to 'understand it all' (Hennink, Kaiser \& Marconi 2016).

\section{Data collection process}

Semi-structured interviews were utilised with an array of open-ended questions in the form of an interview guide. Thus, the direction of the interviews was established (Myers 2019). Throughout the interviews, further elaborations on specific mentions were prompted. Subsequently, recurring themes were noted to allow for additional coding at a later stage (Du Plooy-Cilliers, Davis \& Bezuidenhout 2014).

Apart from making observational notes, accurate data collection was ensured by making audio recordings throughout the interviews. Thereafter, these followed a process of transcribing, allowing for the emergence of themes (Bryman \& Bell 2014).

\section{Data analysis}

The data preparation stage consisted of writing up the transcripts using the audio recordings. Ensuring that ethical considerations were adhered to and the names and all direct relations to the brand in question were removed for anonymity purposes. Verbatim transcriptions were chosen as these allow for the in-depth analysis of content (Hennink, Hutter \& Bailey 2020). Thereafter, the analysis followed a continuous process whereby notes and transcripts were coherently reviewed, leading to a detailed understanding of the data. Additionally, previous literature was considered whilst completing the set objectives.

Using Atlas.ti, various responses were categorised into different generated codes and themes (Friese 2019). Henceforth, content analysis was pursued, which was achieved by a systematic process of working through the individual transcripts to code appearing themes (Harding 2019). 
Following the steps established by Du Plooy-Cilliers (2014), several interpretations were made based on the responses received, thereby identifying emerging themes through a line-by-line coding scheme. Following this process ensured that all lines are read and analysed with great detail, prompting the collection of information in an organised manner (Babbie \& Mouton 2001; Du PlooyCilliers et al. 2014).

\section{Ethical considerations}

The research project was reviewed by the Department of Business Management Research Ethics Committee at the University of Johannesburg, and ethical clearance was granted on 12 December 2019. The ethical clearance code is 2019BM94.

\section{Results}

Introducing a series of acquired results, this section emphasises the findings of the research. Following the results on the demographic profiles, are the findings from the interview questions that revolve around the research objectives of the study.

\section{Demographic profiles}

This section consisted of questions revolving around the interviewees' period of involvement with the brand, duration in the current job position, the role that is played and, finally, the training that they underwent. Following these questions, it was found that the majority of the interviewees (20) had been involved with the brand between 1 and 5 years and over 10 years. Moreover, 12 interviewees have been in their current job position between 1 and 5 years, and 7 interviewees have been in their current positions for over 10 years, with some interviewees reaching durations of up to 38 years. The interviewees were selected based on their roles to meet the sampling requirements. Interviewees' roles ranged from director and dealer principal to accountants and head technicians of the workshop. Additionally, interviewees formed part of the sales team of the dealerships as well as marketing and the parts and accessories departments.

As illustrated in Figure 2, it is evident that interviewees responded based on the training completed.

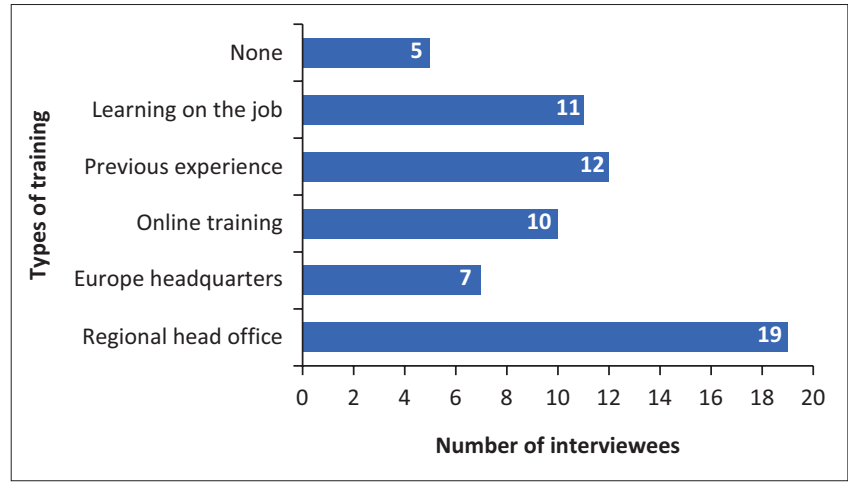

FIGURE 2: Training categories completed by interviewees.
Five interviewees stated that they had not been given any training whilst they would simultaneously agree that the experience gained was purely by doing the job. In addition, six other interviewees confirmed that by working in the job they have gained sufficient experience. Prior experiences mentioned consisted of studies and working in the same job at a different company previously. This prompted 12 interviewees to mention that their experiences gained were either in the same industry, or even in the same position.

Additionally, the online platform provided by the manufacturer, described by an interviewee as an 'electronic learner programme' is available for further training. With all employees having access to this source, it was mentioned by 10 interviewees that they complete as much of the training as possible to increase their knowledge of the manufacturer.

Further training is provided by the headquarters located in Europe. Employees in job positions who require further training, such as managers and head technicians, are 'sent to the factory' in Europe as stated by another interviewee. Head technicians undergo in-depth training programmes on the new motorcycle models released, new technologies implemented, technological advancements on tools and the benefits thereof. This training was described by an interviewee to consist of 'three levels, namely, bronze, silver and *gold'. Managers are also provided with in-depth training revolving around the product offering.

Finally, as described by an interviewee as 'a lot of formal training' is also provided by the regional head office based in South Africa, which most of the employees appear to complete, as stated by 19 interviewees. Whilst most employees complete this, it was stated that this training entails the required knowledge of specific job positions, ensuring the awareness and provision of necessary skills and qualifications to perform various tasks - 'they do a lot of training over the whole spectrum of this business'.

\section{Understanding of strategic positioning and the Fourth Industrial Revolution}

Starting with an understanding of the strategic positioning, nine interviewees mentioned that they were unfamiliar with the term, whilst 14 provided fairly accurate descriptions. These descriptions varied, as two interviewees described the term to entail the placement into a specific job position - 'the way they position you in the brand', done in a targetorientated manner. Three more interviewees from these 14 stated that the term revolves around the location the dealerships are placed in. An interviewee described the term as 'strategically, they make sure that they are in the areas where the demand is'. Additional descriptions provided by six interviewees mentioned the factor of industry competition. An interviewee noted the importance of being unique as a competitor, whilst others mentioned the provision of improved products and services to customers. One interviewee specifically noted the importance to 'strategise 
deals within the marketplace', whilst ensuring an in-depth understanding of the competition occurring in the market. The term strategic planning was additionally mentioned by six interviewees. The importance of having an implemented plan was mentioned by one as 'having the foresight to see what is going to happen', whilst another mentioned the focus of having a business plan in place to ensure the fulfilment of certain requirements to attain 'where you need to be in the future'.

Whilst 14 interviewees provided descriptions and remained to the point, 13 elaborated by applying the term to the manufacturer. It was mentioned that the brand currently owns a strong positioning, described as 'the world's leading manufacturer of sports motorcycles', with further elaborations made on the 'premium components' included in the product development

Moving to the next question, 24 interviewees remained concise in their descriptions of their understanding of the 4IR. Responses varied entailing descriptions of 'technology is evolving' and increased 'digitalisation and automations'. It was noted by an interviewee that the technology had increased significantly on the motorcycles and was described as 'the evolution of motorcycles'.

Furthermore, five interviewees provided direct applications to the brand and the impact created. It was stated that this revolution has led to motorcycles turning to 'more electronic ways' and 'getting more advanced'. Further evolvements and technological advancements were described with additional reference to the diagnostic tools used in the workshop. Interviewees also stated that the increased technology have made certain operations easier.

Finally, seven interviewees expressed sentiments of uncertainty when the term was mentioned. However, following guidance, it was found that only one interviewee was less acquainted with the term, whilst the rest were simply unaware of the era's name.

Whilst interviewees were providing direct relevance to the manufacturer, concern was raised by two. The concern related to the advancements made by technology to a point wherein it is described as 'robots are going to take over'. It was also noted that the 4IR is developing faster than the interviewees anticipated.

Overall, varied descriptions were provided for both the strategic positioning and the 4IR. It was further established that some interviewees required guidance on the terms to answer the questions.

\section{The manufacturer's current strategic positioning}

Interviewees were requested to comment on the manufacturer's current strategic positioning and this was mainly based on personal insights and experiences. Whilst three interviewees were unable to respond to this question, because of their job positions, the rest of the 26 interviewees provided further insights. Here, multiple themes emerged, as indicated in Table 1, allowing for an in-depth understanding on the areas the brand strives in.

Interviewees described the manufacturer as making the right decisions on the locations chosen, providing the 'opportunity to service a specific region'. The 'accessibility through the dealers' to the market was praised as a strength by two interviewees. Further elaborations (2) provided for customer attraction and retention, whereby the manufacturer was described to have implemented the right notions. Additionally, it was mentioned by four interviewees that the existing customers are continuously satisfied in terms of their expectations and demands.

Five interviewees mentioned the opportunity of attracting new markets. It was stated that getting involved with new markets requires a thorough understanding of 'their ways of living'. Simultaneously, it was mentioned that the manufacturer has broadened the motorcycle range, welcoming different customers into the brand. The adoption of a lifestyle, 'a strategy to sell the complete package', was mentioned by four interviewees, as customers go to great extent in purchasing branded clothes, accessories and garments. Additionally, it was proclaimed twice that the brand is purely 'sold on passion', as motorcycles were described to remain a luxury item.

Eight interviewees associated the title of market leader to the brand, and it was established that the catered adventure segment is prevailing. Additionally, an interviewee stated that 'there is no other real competitor on the off-road side' and another stated to be 'on top of the game'.

The declining market was acknowledged by two interviewees. In accordance with three interviewees, however, it was found that the manufacturer is continuously improving the motorcycle

TABLE 1: Emerging themes of strategic positioning.

\begin{tabular}{lc}
\hline Themes & Frequency \\
\hline Market leaders & 8 \\
Leading offroad range & 7 \\
New market opportunities & 5 \\
Strength in the brand & 5 \\
Strategies related to the core values & 5 \\
Satisfying customer demands & 4 \\
Lifestyle adoption & 4 \\
Focused on racing environment & 4 \\
Innovative product offering & 4 \\
\hline Increased technologies & 3 \\
Expanded use of social media & 3 \\
Accessibility & 2 \\
Customer attraction and retention & 2 \\
Revolves around passion & 2 \\
Recognition of declining market & 2 \\
Stable warranty system & 2 \\
Prevailing adventure range & 1 \\
Uniqueness & 1 \\
\hline
\end{tabular}


technologies, whilst four others stated that the product development and offering are becoming increasingly innovative, allowing the brand to 'open up to a different market'.

Furthermore, five interviewees specifically placed the dominating strategic positioning with the notion that the strength is found in the brand itself, and an interviewee stated that 'leading in the market in a lot of fields'. Five times it was mentioned that the product development strategies implemented are always directly related to the core values 'whatever we develop, we firstly look at what our core values are'. Another aspect was based on the insight of two interviewees who mentioned the unique and effective warranty system.

Overall, the motorcycle manufacturer is regarded as having a strong current strategic positioning. The perception is that the manufacturer consists of a strong brand, and this established the link to market leadership. Thus, the various emerging themes, listed in Table 1, were found to contribute to the brand's success.

Based on the responses previously received, interviewees were asked whether a link exists between strategic positioning and the 4IR. Most of the interviewees (20) agreed to the existence of this link.

As depicted in Figure 3, this link was motivated by the increased use of improved diagnostic tools as well as the wider utilisation of social media. An interviewee motivated this: 'I think it does. I think being a leader of product development, of technology, of social media, of certain applications and new apps that will come along'. The brand was labelled to be 'ahead' in terms of technology by three interviewees, providing additional confirmation on the link of two aspects.

The five interviewees who declined the idea of the link stated that South Africa is not prepared for the changes brought forth by the 4IR - 'I don't see the mobility or electrification in this country being where it is in Europe in the next ten years'. In support of this dismissal, the following was stated by an interviewee: 'click-through rates and likes do not bring additional customers in'.

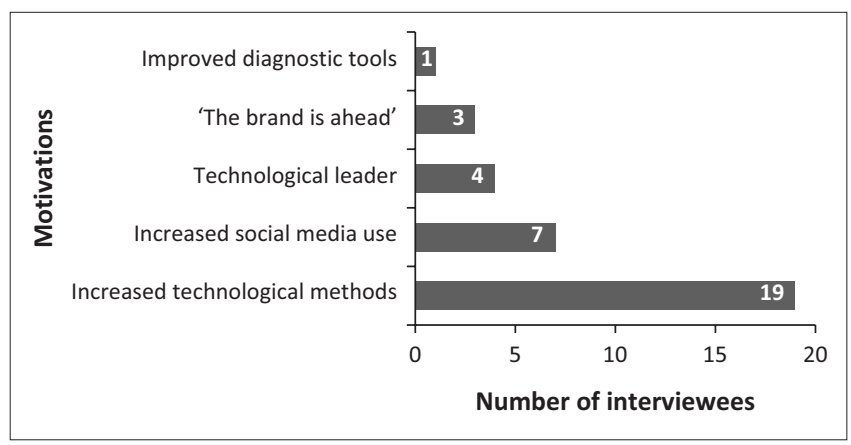

FIGURE 3: Emerging motivations in agreement to the link between strategic positioning and Fourth Industrial Revolution.
In summary, it is believed that a link exists between the strategic positioning of the manufacturer and the 4IR. Whilst it was reiterated that the link was based on the technological advancements, it was noted that the manufacturer has been labelled as the technological leader. This is evident in the elaborations entailing product developments and advancements that are described to be increasingly innovative.

\section{Strategic capabilities of the motorcycle manufacturer}

Interviewees were requested to indicate their perception on the strategic capabilities of the manufacturer and 15 responded. The most common strategic capability resulted because of the brand itself, as was mentioned by 17 interviewees and this was followed by the product development, which was noted by 11 interviewees. The brand itself was described by a few interviewees as follows: 'we have got a quality product'; 'reliability and service, I think that is definitely the strengths of the brand' and 'it's the brand. 'It's the Porsche of bikes' and 'we are a very high-end brand'.

It was stated by an interviewee that the brand offers a 'much wider offering than the competitor', additionally complimented by increased technological advancements, described to be achieved through thorough Research and Development (R\&D). High levels of customer satisfaction were mentioned by five interviewees - the 'biggest advantage is that they are really good at looking after their own customers', with further mentions made on the increased popularity of the off-road racing scene, as an interviewee explains the need for 'having the necessary models to target different markets'.

The competitive advantage was reaffirmed by 12 interviewees who mentioned the technological advancements and product development. Additionally, four interviewees repeated the market leadership title. According to six interviewees, customers are satisfied as their demands for increased technologies, in accordance with the changing environments, are met.

Overall, a multitude of strategic capabilities was mentioned by the interviewees. From the various mentioned capabilities, only five are specifically noted as important in the attainment of competitive advantage, namely, 'market leaders', 'strong brand', 'customer satisfaction', 'improvements' and 'technological advancements'.

\section{Strategic changes over the past decade}

The interviews provided an understanding of the changes that the manufacturer has undergone through the past decade. This allowed for obtaining an indication of how far the manufacturer has come in terms of strategic changes, according to previous environmental changes. A pattern around four themes emerged, specifically, namely, the motorcycle, technology, the brand and the market; and these are repeating themes amongst the interviewees, seeing that a high frequency of mentioning was achieved. 
To begin with, the motorcycle category was divided into three groups where the changes have been most apparent. Figure 4 depicts these individual categories.

Interviewees mentioned the significant engine changes from 'carburetted versions to fuel-injected systems', followed by the observation around the expansion of the product offering, and finally the introduction of new products. It was noted by 13 interviewees that technology has undergone drastic changes, with an interviewee describing that the motorcycles 'have improved so much'. Whilst the manufacturer was further characterised as a 'massive technology leader', and this was motivated by the continuous improvements and technological advancements. Further technological advancements were found to revolve around the implemented software and systems, leading to another statement that this makes 'it safer for customers to ride the bikes, for inexperienced riders', as elaborated by an interviewee.

Another aspect mentioned by an interviewee was that the increased technologies are responsible for the changes occurring in the market. Today's customers were described to be a lot more informed - 'they probably know more about whatever they want to buy than the actual salesman trying to sell it'.

The next category of changes revolves around the brand. Comparing to when the manufacturer initially started operating in South Africa, it was stated by 11 interviewees that the brand has now acquired a big piece of the market share. The brand's appeal was described to have changed over the years and a 'more premium' image was created. The data set further established that the brand is now recognised as a benchmark in the motorcycle industry. Another strategic change was described to be the broadening of the product offerings, as this was noted to invite a wider market.

Overall, interviewees touched on the drastic changes brought on by technological advancements in the past decade whilst the manufacturer has also increased its corporate image, entailing the characteristics of quality and reliability. Then further mentioned strategic changes entail the broadened range of product offerings whilst being more inviting to new markets.

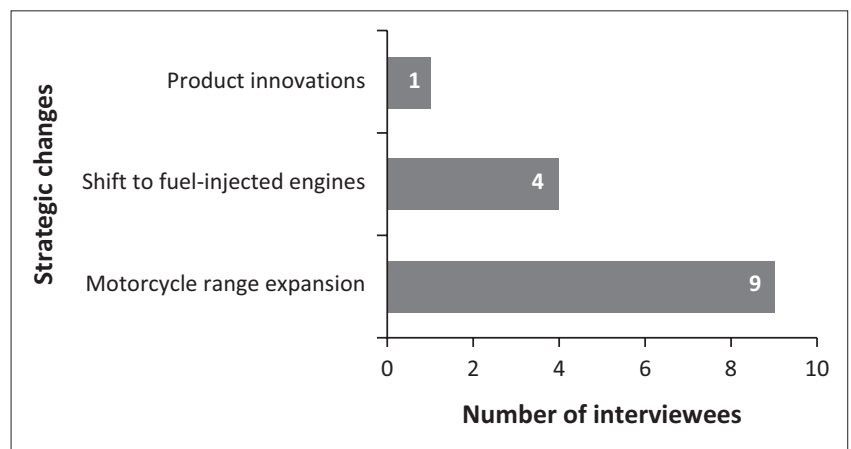

FIGURE 4: Most apparent strategic changes.

\section{Suggested strategies to position the motorcycle manufacturer in South Africa for the Fourth Industrial Revolution}

Twenty-three interviewees provided suggestions and the rest stated that the brand should continue operating and making decisions the way they do, as it is working well 'the brand is doing it already'. The data analysis revealed the emergence of eight different themes in this regard. Refer to Table 2.

It was suggested by four interviewees that the dealership employees and representatives should spend more time with customers - 'go and ride with your customers'. A suggestion in this regard is to be 'planning more rides together'. In addition, four interviewees considered this in a more personal manner and suggested that better systems should be implemented for specific job positions.

The increased use of social media was mentioned by six interviewees, which was described as allowing customers 'to interact more with the brand', and this was suggested in combination with acquiring new target markets because of the changing environments and the growth of technology on a global scale.

It was emphasised by six interviewees that the manufacturer should keep up with technology, whilst further five stressed the importance of staying up to date with the changes in the market environment and changing customer needs. In summary, different suggestions were provided which mainly entailed permanent modifications to technology and environmental changes.

\section{Discussion}

Similar to the results section, the discussion is structured according to the demographic descriptors and the secondary objectives of this study.

\section{Demographic description}

It was found that many of the interviewees had been employed with the manufacturer for relatively long periods of time. One interviewee even described the employment period of 16 years with the manufacturer. Whilst this could provide employee satisfaction, it was also found that some of the interviewees had only recently been employed. This additionally shows that the manufacturer is still hiring new

TABLE 2: Interviewees' suggestions.

\begin{tabular}{lc}
\hline Suggestions & Frequencies \\
\hline Targeting of other markets & 7 \\
Increased social media interaction & 6 \\
In agreement with the brand's decisions & 6 \\
Keeping up with changes & 5 \\
Increased customer engagement & 4 \\
Implementation of improved systems & 4 \\
Keeping up with technology & 2 \\
More technically minded & 1 \\
\hline
\end{tabular}


staff, looking to expand skills within the brand, as the brand is found to experience further growth.

The sampled interviewees, all employed by the manufacturer, played a variety of roles that ranged from managing director and dealer principals to sales executives, accountants, workshop technicians and even marketing and sales managers. The multitude of roles provided for an indication of the differing training provided, according to the job positions. Whilst the interviewees are trained according to their job specifications, it appears to be a standard procedure for the employees of the manufacturer to receive training at the regional head office in South Africa. It was further established that those employees working at the regional head office are sent for further training to the brand's headquarters in Europe. It was determined that this is done to ensure maximum learning of skills and the acquisition of qualifications and meeting every expectation and demand customers may have.

Training is also available on the online platform, which most employees seem to complete. It was found that most of the interviewees spoke to complete the online training out of their own will to further their knowledge. Interviewees want to own the necessary skills to carry out specific tasks as efficiently and effectively as possible. Even when employees were found to be employed in a different job position, the interviewees stated that the acquisition of additional knowledge can only be to their own benefit. However, it was established that some interviewees had not undergone any training whatsoever.

Overall, an increased level of customer satisfaction was noticed, which could play a key role in the manufacturer's title as the market leader. Additionally, training is provided on a multitude of levels, ensuring the staffs are provided with the resources to develop their knowledge and skills.

\section{The understanding of strategic positioning and Fourth Industrial Revolution}

Hedreen (2019) stated that appropriate decision has to be made by managers to further ensure growth and development of a manufacturer. Additionally, Porter (2001) affirms that strategic positioning entails the in-depth understanding of a brand's competitors, whilst setting up a plan to set themselves apart in a manner unique to the industry. The importance of strategic planning was elaborated by the interviewees, which is in concurrence with Gartenstein (2018), allowing for future planning to be made to achieve certain goals and the envisioned strategic positioning.

Sustainability was mentioned by some interviewees in direct collaboration with the factors established to effectively manage competitive advantages, as was set out by Bateman et al. (2019). Although it was found that many interviewees understand a certain aspect of strategic positioning, some are less acquainted with the term and, thus, lack the understanding of the importance thereof.
Interviewees' understanding of the 4IR includes the rapid occurrence of innovations (Schwab 2016). Increased automation of manual operations in manufacturing industries was additionally mentioned. This was noted to be achieved through technological advancements and increased globalisation (Low 2019). It was, thus, noted that the interviewees understand what the term entails as well as the implications. It was further established that the manufacturer does well to keep up with the technological and innovative changes, through the improvisation of development and manufacturing processes.

\section{The manufacturer's current strategic positioning and capabilities}

By describing the strategic positioning of the brand, it was found that these are modified and adapted in accordance with the competition. Reaffirmed by Porter (2001), it was stated that the brand continuously seeks to improve services, products and operations to ensure further acquisition of competitive advantages.

Overall, it was found that the manufacturer currently has a dominant strategic positioning, as the products are developed in an innovative manner. This allows for the meeting of customer expectations (Dean and Company 2020).

A direct link was found between the manufacturer's strategic positioning and the 4IR. The manufacturer has proven flexibility in the modifications of strategies. Allowing for increased employment opportunities whilst maintaining the adequacy and level of training staffs for the changing environments was additionally found to confirm the relationship (Gaspar, Juliao \& Cruz 2019).

The manufacturer is regarded as implementing strategies based on value-added customer and increased competitive advantage. As a result, multiple strategic capabilities were listed, proving the notion that the target market is served in a valuable manner through effective strategic implementation (Gamble et al. 2017:2).

Therefore, the brand is seen as a strategic capability, continuously adding value to the manufacturer and its customers. The broadening of the product offering serves as an additional capability, which is supported through a vast amount of knowledge spill over (Frenken 2007, quote by Kublina 2015).

In summary, an advanced brand was established, continuously maintaining and gaining competitive advantages. Whilst sustainability has been evident along the strategies, the manufacturer has ensured survival as well as an increased share in the market (Anonymised Authors 2019b).

\section{Exploring current strategies}

The manufacturer was found to follow a diversification strategy as business operations entail a unique competitive 
advantage whilst ensuring the targeting of a broader market (Le 2019; Porter 1985). This was supported by the strategies including the broadening of the range, with increased technologies, features and applications.

Concerning the brand's flexibility, the brand adapts strategies ensuring a strong strategic positioning according to changing market environments (Cloosterman 2018). Additionally, achieving customer satisfaction forms part of the decision-making of strategy implementation, ensuring the meeting of expectations and demands. This has been established by providing a product characterised as premium quality and performance. For this, staffs are adequately trained, ensuring the adoption of appropriate skills and increased knowledge to provide customers with the best possible service (Anonymised Authors 2019a). This further forms part of the development strategy as a variety of innovative decisions are made whilst including the ultimate technological advancements (Kylliäinen 2018).

\section{Suggested strategies for strategic positioning within the Fourth Industrial Revolution}

The declining market was acknowledged by the interviewees. Thus, it is deemed important for the brand to create the necessary value-added strategies such as increased customer engagements, further improving customer service and motivating customers to continue spending their money in the industry. However, these prove to be difficult with the depreciating South African rand currency (Droppa 2018).

The value-added strategies led to the suggestion that further markets be targeted appropriately, ensuring business and achieving more sales. Thus, the diversification strategy and, more specifically, the concentric diversification strategy cater to the increased technologies and skills to meet specific market requirements (Le 2019).

Concentric diversification strategies will increasingly become of benefit as the 4IR becomes more digitalised. Specifically targeting technological advancements, this strategy goes hand in hand with the suggestions provided for the implementation of adequate online platforms, catering to the technologically adept customers wanting to make online purchases (Ndung'u \& Signé 2020).

Although many of the interviewees did not provide further suggestions apart from agreeing on the current strategies implemented, it was established that the manufacturer has a strong positioning in the market. The interviewees have expressed confidence in the brand and the advancements, providing support in the strategic decisions.

Furthermore, some interviewees were less acquainted with the strategies implemented by the manufacturer. Often this was reasoned with specific job positions, as interviewees were not confronted by the strategies. Some were also less knowledgeable on the motorcycle industry, thus only being able to provide detailed information once prompted, assisted or guided.

\section{Limitations}

The strengths of this study involved the researcher's ability to connect with the topic at a personal level. This is because of her experience, interest and profound knowledge of the motorcycle industry.

Limitations were experienced when the interviewees expressed confusion about academic terminology or even jargon used in the industry. This rendered interviews more difficult, as the passion for the industry was not equally shared by all interviewees, let alone the understanding of the intricacies. Also note, not all interviewees have a profound understanding of business and strategic management. Therefore, certain aspects were previously not even thought of.

\section{Recommendations}

Relative to the data collected and analysed, suggestions and recommendations were construed. Whilst some are based on the potential observed problems, others revolved around the upkeep or increased focus on specific aspects, ensuring a competitive advantage within South Africa.

The initial recommendation entails the increased training of employees. Because of the uncertainty expressed around the terms strategic positioning and the $4 \mathrm{IR}$, it is suggested that further training is implemented, allowing for the acquisition of knowledge around the topics of increased digitalisation, technological advancements and the affect thereof on the manufacturer's strategic positioning. It is important for the employees to be acquainted with the strategic positioning of the brand as well as with the current implemented strategies. This will enable them to contribute to the growth and strengthening of the positioning, which applies to the 4IR. Whilst many employees are aware of technological growth and increased digitalisation, the consequences and outcomes are feared. Thus, ensuring further training to increase skills and qualifications is beneficial to the manufacturer, as employees have the necessary knowledge to perform specific tasks, whilst instilling confidence that employees' positions will not become redundant (Brightman \& Moran 2001).

Further recommendations entail constant in-depth examinations of the market to establish new arising demands and trends amongst customers, such as better navigation systems, the possibility of electronic suspensions and electric engines. These should be identified in accordance with the changing market environments because of technological advancements rendering an increasingly dynamic market of digitalisation. Whilst it was found that the manufacturer reinvests many resources into $R \& D$, it was established that this strategy be maintained. This will ensure that the market and the demands are continuously understood and catered for, allowing for increased competitive advantage and the acquisition of further market share.

Increased attention is required on the movement to e-commerce and the $4 \mathrm{IR}$, providing customers with more 
opportunities to make online purchases. This becomes a more relevant change in South Africa and it is suggested that the manufacturer increases the utilisation of e-commerce and online platforms, enabling customers to make purchases from the comfort of their homes. It is additionally advised to collaborate with a well-known second-hand dealer who has created an application for motorcycles to be decided on and purchased via an online video feed (Morton 2020). This collaboration or outsourcing of activities could allow for additional sales.

The manufacturer was found to follow a diversification strategy accomplished through the implementation of core values and philosophies whilst the product development includes increased technological advancements. This has resulted in customer satisfaction whilst additionally meeting their expectations and increasing the product offering (Mitterreiter 2018) manufactured of premium components (Anonymised Authors 2019a). Achieving a strong positioning, it is suggested that this is maintained through the implementation of a corporate-level growth strategy, ensuring a strong foundation for survival. Additionally, an element of related or growth diversification and concentric diversification (Le 2019) is suggested to be used further, as the manufacturer continues to outsource activities and increasingly using prevailing resources, saving costs and time whilst meeting differing expectations (Furrer 2016).

The response of five interviewees who are not of the opinion that the 4IR will succeed in the South African market may require further investigation. Although it may be a weak signal, this can prove to be powerful in the long-term. Therefore, it is suggested to conduct further studies on the impact of the 4IR in terms of technological innovations and mainly electronics on consumer satisfaction over the long-term.

\section{Conclusion}

To conclude, evidence provides for the declining motorcycle market in South Africa, with new challenges and potential opportunities introduced through the 4IR. Despite the circumstances, the manufacturer possesses a strong strategic positioning with the market leadership title. Thus, in conclusion of the research question - 'How should the motorcycle manufacturer within South Africa position itself strategically in the Fourth Industrial Revolution to gain a competitive advantage?' - it is deemed necessary for the manufacturer to continuously adapt and modify strategies, according to identified changing demands. This also then supports the primary objective, namely, to determine the motorcycle manufacturer's strategic positioning for the 4IR in South Africa, ensuring a competitive advantage within the South African motorcycle industry.

Although developments of the product offering are observed to be immense, the manufacturer must maintain and increase standards to attract new customers. These standards include continuous improvements and additions of technologies, new features and apps as well as further innovative developments to the individual motorcycle components of increased quality (i.e. engine, chassis, exhaust systems and frame). Therefore, the accurate implementation of strategies is required to target customers whilst ensuring the achievement of prosperous customer engagement in the 4IR.

\section{Acknowledgements}

The article is based on a master of commerce dissertation in strategic management, entitled 'Strategic Positioning for the Fourth Industrial Revolution: The case of a motorcycle manufacturer' which was conducted by Z.J.B. under the supervision of D.R.

Z.J.B. would like to take this opportunity to thank the supervisor and co-author, D.R. for all the assistance and sharing of knowledge and expertise in the writing of this article. Z.J.B. would also like to express gratitude to Prof. D. Pooe for the time and assistance provided.

Also, Z.J.B. would like to express a massive thank you to her mother, Turid, without whom all of this would not have been possible.

\section{Competing interests}

The authors declare that they have no financial or personal relationships that may have inappropriately influenced them in writing this article.

\section{Authors' contributions}

Z.J.B. and D.R. evenly contributed to the writing of this article.

\section{Funding information}

This research received no specific grant from any funding agency in the public, commercial or not-for-profit sector.

\section{Data availability}

The data that support the findings of this study are available from the corresponding author, Z.J.B., upon reasonable request.

\section{Disclaimer}

The views and opinions expressed in this article are those of the authors and do not necessarily reflect the official policy or position of any affiliated agency of the authors.

\section{References}

AFP.com, 2019, [placement manufacturer] turned record profits in 2018, viewed 06 August 2019, from https://www.timeslive.co.za/motoring/news/2019-01-30[placement manufacturer]-turned-record-profits-in-2018/

Alexander, M., 2015, Why your business strategies must constantly change, viewed 06 August 2019, from https://www.cio.com/article/2969563/why-your-businessstrategies-must-constantly-change.html 
[Anonymised Authors], 2019a, 2022 [placement manufacturer] plan, unpublished manuscript.

[Anonymised Authors], 2019b, [placement manufacturer], viewed 12 September 2019, from https://www. [placement manufacturer].com

Babbie, E. \& Mouton, J., 2001, The practice of social research, Oxford University Press, Cape Town.

Bateman, T.S., Snell, S.A. \& Konopaske, R., 2019, Management: Leading \& collaborating in a competitive world, 13th edn., McGraw-Hill Education, New York, NY.

Brightman, B.K. \& Moran, J.W., 2001, 'Managing organizational priorities', Career Development International 6(5), 244-288. https://doi.org/10.1108/ EUM0000000005581

Bryman, A. \& Bell, E., 2014, Research methodology, Oxford, Cape Town.

Cloosterman, M., 2018, 5 keys to brand positioning implementation, viewed 12 September 2019, from https://www.brandingstrategyinsider.com/5-keys-tobrand-positioning-implementation/\#.X1c7X1UzblU

Cokayne, R., 2016, SA motorcycle sales looking grim, viewed 16 July 2019, from https://www.iol.co.za/motoring/bikes/bmw/sa-motorcycle-sales-looking grim-197392

Dean and Company, 2020, Strategic positioning, viewed 02 July 2019, from https:// dean.com/delta-model/strategic-positioning/

Denzin, N.K. \& Lincoln, Y.S. (eds.), 2008, The landscape of qualitative research, 3rd edn., Sage, Los Angeles, CA.

Droppa, D., 2018, Where to now for SA motorcycle industry?, viewed 16 July 2019, from https://www.iol.co.za/motoring/bikes/where-to-now-for-sa-motorcycleindustry-15246872

Du Plooy-Cilliers, F., Davis, C. \& Bezuidenhout, R., 2014, Research matters, Juta, Cape Town.

eNatis, 2019, New Vehicle Registrations (Article 141), viewed 02 July 2019, from http://www.enatis.com/index.php/statistics/14-new-vehicle-registrations

Etikan, I., Musa, S.A. \& Alkassim, R.S., 2016, 'Comparison of convenience sampling and purposive sampling', American Journal of Theoretical and Applied Statistics 5(1), 1-4. https://doi.org/10.11648/j.ajtas.20160501.11

Friese, S., 2019, Qualitative data analysis with ATLAS.ti, 3rd edn., Sage, London.

Furrer, O., 2016, Corporate level strategy: Theory and applications, 2nd edn., Routledge, London.

Gamble, J.E., Peteraf, M.A. \& Thompson Jr., A.A., 2017, Essentials of strategic management: The quest for competitive advantage, 5th ed, McGraw-Hill management: The quest

Garrett, R.P.J. \& Welcher, T. (eds.), 2018, Corporate entrepreneurship as a survival routine, Emerald, West Yorkshire.

Gartenstein, D., 2018, Why is strategic planning important to an organization? viewed 16 July 2019, from https://yourbusiness.azcentral.com/strategic-planningimportant-organization-4103.htm

Gaspar, M., Juliao, J. \& Cruz, M., 2019, Organizational strategies induced by the Fourth Industrial Revolution: Workforce awareness and realignment, viewed 15 August 2019, from https://www.researchgate.net/publication/325541331 Organizational_Strategies_Induced_by_the_Fourth_Industrial_Revolution Workforce_Awareness_and Realignment

Harding, J., 2019, Qualitative data analysis: From start to finish, 2nd edn., Sage London.

Hedreen, S., 2019, Techniques and tools to help you make business decisions, viewed 08 February 2021, from https://www.businessnewsdaily.com/6162-decisionmaking.html

Hennink, M., Hutter, I. \& Bailey, A., 2020, Qualitative research methods, 2nd edn., Sage, London.
Hennink, M.M., Kaiser, B.N. \& Marconi, V.C., 2016, 'Code saturation versus meaning saturation: How many interviews are enough?', Qualitative Health Research 27(4), 591-608. https://doi.org/10.1177/1049732316665344

Hickman, C.R. \& Silva, M.A., 2018, Creating excellence: Managing corporate culture, strategy, and change in the new age, Routledge, London.

Kublina, S., 2015, 'Related variety, unrelated variety and regional growth: Development patterns and role of absorptive capacity', Regional Studies 20(1), 2-5.

Kylliäinen, J., 2018, Innovation strategy - What is it and how to develop one?, viewed 25 February 2019, from https://www.viima.com/blog/innovation-strategy

Le, H., 2019, 'Literature review on diversification strategy, enterprise core competence and enterprise performance', American Journal of Industrial and Business Management 9(1), 91-108. https://doi.org/10.4236/ajibm.2019.91008

Low, A., 2019, 'Technical standards for smart manufacturing: Evolution and strategic positioning', in Smart factories: Issues of information governance, Manufacturing policy initiative, School of public environment affairs, pp. 17-24, Indiana University, Bloomington, IN.

Mitterreiter, S., 2018, '[placement manufacturer] and [placement manufacturer]: An [placement manufacturer] partnership in the motorcycle industry', in S. Schmid (ed.), Internationalization of business, pp. $99-123$, Springer, Berlin.

Morton, S., 2020, Introducing... Fire it up! Fastrack!, viewed 24 August 2020, from https://www.zabikers.co.za/2020/05/21/introducing-fire-it-up-fastrack/

Mtanga, S., 2016, SA motorcycle industry: Challenges \& opportunities - Inputs to the SA automotive policy \& masterplan, viewed 16 January 2020, from https://www. tips.org.za/events/development-dialogue-seminar/item/download/1298_99b5a c6dc750f79151bb8af02a490684

Mtanga, S. \& McCamel, R., 2019, Motorcycle parts and aftermarket industry regiona value chain in southern Africa, Working Paper 38, UNI-WIDER, Helsinki.

Myers, M.D., 2019, Qualitative research in business and management, 3rd edn., Sage, London.

Naudé, W., 2017, Entrepreneurship, education and the Fourth Industrial Revolution in Africa, IZA Institute of Labor Economics, Bonn.

Ndung'u, N. \& Signé, L., 2020, The Fourth Industrial Revolution and digitization will transform Africa into a global powerhouse, Foresight Africa 2020, Washington, DC.

Porter, M.E., 1980, Competitive strategy: Techniques for analyzing industries and competitors, 1st edn., The Free Press, New York, NY.

Porter, M.E., 1985, Competitive advantage: Creating and sustaining superior performance, The Free Press, New York, NY.

Porter, M.E., 2001, Strategy and the internet, viewed 12 September 2020, from https://hbr.org/2001/03/strategy-and-the-internet.

Prabhakar Rajkumar, D.K. \& Abraham, M., 2018, 'Strategic positioning and sustainable competitive advantage for growth of industry', Shanlax International Journal of Management 5(2), 160-167.

Saunders, M., Lewis, P. \& Thornhill, A., 2019, Research methods for business students, 8th edn., Pearson, Harlow.

Schwab, K., 2016, The Fourth Industrial Revolution, viewed 13 April 2019, from https://www.weforum.org/about/the-fourth-industrial-revolution-by-klaus schwab/

Sutherland, E., 2019, 'The Fourth Industrial Revolution - The case of South Africa', Politikon - South African Journal of Political Studies 47(2), 233-252. https://doi.or $\mathrm{g} / 10.1080 / 02589346.2019 .1696003$

Thanh, N.C. \& Thanh, T.T.L., 2015, 'The interconnection between interpretivis paradigm and qualitative methods in education', American Journal of Educational Science 1(2), 24-27.

Van der Walt, D., 2017, Motorcycle review: [placement manufacturer], viewed 15 August 2019, from https://www.wheels24.co.za/BikesQuads/NewModels/ motorcycle-review-[placement manufacturer]-20171016 